\title{
HOLISTIC VISION: INTEGRATIVE APPROACH IN GUIDANCE AND COUNSELING SERVICES
}

\author{
Ade Hidayat \\ Program Studi Bimbingan dan Konseling FKIP \\ Universitas Mathla'ul Anwar Banten \\ adehidayat@unmabanten.ac.id
}

\begin{abstract}
The philosophical issues in Guidance and Counseling especially in epistemological discourse have made paradigmatic friction that pointed by some issues from therapeutic-clinical to comprehensive way with preventive development perspective approach. It was also caused by the wider friction where quantum physic has remove classic Newtonian one, then the influence has generally removed another disciplines, where Guidance and Counseling in one of them. Through the comprehensive paradigm, Guidance dan Counseling need to take prepare the expert in order to capable to develop integrated and comprehensive thinking awareness. It means the Guidance and Counseling holistic vision is urged. Through the holistic vision, all of the competency of student is noticed integrally, such as intellectual, emotional, social, physical, artistic, creativity, ecological awareness, and spiritual competencies.
\end{abstract}

Keywords: Ecoliteracy, Holistic Vision, Guidance and Counseling of Comprehensive.

\section{INTRODUCTION}

The progress of science today is rapidly proven by a much-emerging theory of knowledge and technology. Science always happens improvisation of theory/ concept, simple to the theory/concept more perfect. Similarly to the field of guidance and counseling. Early development of counseling and psychotherapy influenced by psychodynamic, respectively influence of cognitive, behavioristic, humanistic and systems perspective become into the paradigm of guidance and counseling services (Sanyata, 2013: 1). The issue of philosophical counseling primarily in an epistemological study has brought a paradigmatic shift indicated by issues concerning clinical therapeutic toward a more comprehensive throughdevelopmental preventive approach.

Changes in the motion of Guidance and Counseling (BK) thought in line with the theory of the movement of history that is dialectic. The dialectical worldview mention that history is moving in a spiral moving steadily upward toward perfection. history is not linear, that an event just for once that will not be repeated (einmalig), because in history there will be changes, history is not cyclical like the wheel because the change is not returned to the starting point, but to a higher point and more perfect.

Then, like a spiral, a paradigm shift towards such a comprehensive BK back to the historical tradition of old thought (ancient) with some reforms that are tailored to the current condition to a process of "perfection". The paradigm is the result of improvisation synthesis of previous ideas. In fact, if you see the trajectory of the historical development of the paradigm of science globally (West), where the influence of quantum physics has shifted the paradigm of classical physics Newtonian, then the effect of the widespread shift the paradigms of other 
disciplines, including the field of counseling and psychotherapy, the comprehensive approach in guidance and counseling evolving today can be called also influenced by the paradigm shift. The existence of this paradigm shift by Capra (1991) can not be separated from the influence of the ideas of ancient oriental traditions, particularly Taoism.

\section{DISCUSSION}

Fritjof Capra (1991) describes the paradigm shift of thinking that are widely used in a variety of disciplines, is based on the idea of classical Newtonian physics to quantum physics way of thinking, this is because of the influence that changed the human perspective of the universe and life. Capra further said that the paradigm shift is influenced mainly by the paradigm shift in science (West) because there is the influence of Eastern thought, particularly Taoism.

Classical physics theory explains that the basis of all matter is a particle, the force between particles (gravity) and motion. This is what underlies the universe. All events can be reduced to the physics of the motion. This is according to Capra (1991: 56) affect the paradigm at the time of the initiation of this theory, that everything is seen mechanistically, can be determination clear and predictable manner, and always there is a causal relationship between all the events.

The paradigm of classical physics then shifted with the rise of quantum physics discoveries. Through quantum physics, people begin to change the way of thinking of the all-precise, predictable, to the relative and probabilistic thinking. It is further described Capra (1991: 19) in accordance with the thinking of the East more mystical-transcendent, comprehensive, and global. This way of thinking is based on quantum physics was in accordance with the way of thinking of Taoism. In Taoism, thinking is more metaphysical, intuitive, and harmony. According to Taoism, all of the events is a description of the essential nature yinyang, two dynamic poles are constantly in touch harmony. Yang that is fully by nature aggressive, demanding, lust beat forward ratios, can be integrated and developed through integration with behavioral Yin that quiet, responsive, cooperative, and intuitive (Capra, 2000: 38). Blended these two poles harmonious expands as far as the human behavior that is independent, peaceful, collaborative minded and environmental conscious. For Taoism, something that is contrary can coexist and positive consequences. In the East the idea, people think more thorough, more global, more balanced, and accept contradictions within.

The idea of quantum physics was affecting all areas of science, such as in the medical world (medicine) where the known models of infomedic removed biomedical deterministic models and dwell on the physical illness as such. Model infomedic appears to be different by offering an understanding that human beings are creatures who have integrity (holistic) body-soul in an open-system so complex, then handling of the patient no longer partial, but a more thorough review both aspects of physical, social, psychological, and spiritual. In the pharmaceutical world is now known as the patient-oriented approach that is not oriented to the drug. So it seems that the approach to the sick people more humane, comprehensive, more integrated, and holistic. In the realm of psychology, this effect can be seen with the shift from deterministic patterns of thought, logical, mathematical, and everything being measurable, as reflected in both psychoanalysis and behavioristic thinking.

In psychoanalysis, the process approach uses the influence of the past as something that determines an individual as a result of the formation in the present, 
which in the sense that what the root of the problem or crisis experienced by the individual at this time can be predicted by looking at past events or experiences. In line with behaviorism in the assumption that human behavior is the key for understanding the human subject. The bearers behavioristic want equality psychology to physics (classical), both in methodology and validity of the studied data. Watson is a figure who focuses on the aspects of physiology, in the particular, physiology of the brain. Skinner otherwise overrides the physiology of psychological theory by asserting behavior as an act of organisms to the top of the natural realm. According to Skinner, all mental phenomena can be understood and explained by analyzing the behavior that seemed based on stimulus-response models.

Real that paradigm of quantum physics is widely used in other fields, including in the framework of the theory of guidance and counseling. The shift of the BK service-oriented approach to the crisis is a clinical-therapeutic service with a comprehensive approach towards the preventive-oriented perspective to the development of a systems approach.

Preventive development approach and system approach as a pressure point in the comprehensive service paradigm BK is a dialectic synthesis in the field of Guidance and Counselling thinking. The series of shifting theories of counseling and psychotherapy begins with the Freudian concept, then successively born behavioristic approach, humanistic and paradigms systems also influence the development of guidance and counseling services. Since the mid-2oth century, the development of counseling and psychotherapy are dominantly influenced by humanistic although other approaches still have a significant contribution. The paradigm shift of guidance and counseling is an overview of the needs and demands of society on the pattern of guidance and counseling services. Guidance and counseling become a basic need to be developed in the education sector and provide recommendations that every human being is directed to developing the condition of what is towards what should be (Kartadinata, 2011: 9). Some last decades a comprehensive approach to guidance and counseling has been used widely, also in Indonesia. Comprehensive Paradigm emphasis on a systems approach, in which the intervention targets no longer focused on the individual, but the system environment in which counselees are also intervened for a guarantee to the effectiveness of the development potential of the counselee (Blocher, 2000).

Based on the above, the reform of BK paradigm over the direction of comprehensive real is not something totally new. This is a kind of turning point in the approach that has been used modern psychology to return to the "wisdom" at the time of traditional approaches, particularly in Eastern wisdom. In the perspective of Osman Bakar (Purwadianto et al., 2004: 108), modern psychology discipline failed to deliver a free and authoritative because it is too dependent on physics (classical) and physiology. So it is not an exaggeration to say that modern psychology was in chaos. This is inevitably caused by mechanical materialism prison confines.

Modern psychology is in crisis and deadlock to interpret human, because only focused his research on empirical matters only. It is marked for example by shifting the understanding of psychology as "the science of the soul" to be more to the behavior (behavior) that only learn about "symptoms of the soul". Though psychology should not only discuss the facts of reality, but also examine and observe the other dimension that the sources of the mental events are (Gojali, 
2012). Because life is very multi-complex human behavior, not only be approached through studies that look, only influenced by physical factors-biological, psychoeducation, and socio-culture but there are other dimensions as the source of human life, the spiritual dimension. According to Viktor E. Frankl (2004: 49) in the logotherapy theory, the spiritual dimension is touched on Noetic term as the equivalent of spirituality. This logo therapy theory paves the way for the emergence of a new stream of discourse psychology that became a trend in the Western world today (especially American), of transpersonal psychology. Many belief that this approach was inspired by the Orient with Taoism or as Sufism is deeply rooted from Islamic sources.

\section{Eco-literacy in the Comprehensive Guidance and Counseling}

The concept eco-literacy is seen as a distinctive contribution Capra is essentially derived from the traditions of oriental thinking can be defined as a situation of intelligence or a thorough understanding of the workings of the principles of ecology in the common life of the planet towards a sustainable life (sustainability). Capra originally just used the generic term ecological awareness (ecological). The emergence of the concept of eco-literacy associated with a new perspective championed Capra and his colleagues through the institution of Center of Ecoliteracy in 1995 to mobilize the public to have a new understanding of the reality of their life together on planet earth and carry out the necessary reforms.

Common life on planet earth longer be regarded not mechanistically but ecologically as well as systemic. Life together should be seen as a series of living systems which form an extensive network. In order to cement a life together, then the guidance and counseling must be present to knit vast networks (social). Special education in guidance and counseling services can contribute to the gathering and instill the values, knowledge, and skills with the development of individuals associated with the interests of the establishment of sustainable communities. Guidance and counseling services can practice a pedagogy based on individual development oriented to the formation of a solid understanding of life. In other words, eco-literacy pedagogy should be developed through networks that can be built extensively, and its network development must be based on the system and individual development. The systems approach and developments in guidance and counseling services (developmental counseling) have been formulated in the pattern of a comprehensive guidance and counseling services are adopted from ASCA national model (Sanyata, 2013).

Blocher (2000) explained that the counseling development (developmental counseling) is not only aimed at people more independent of encountered feeling but also aims to build a social network life appropriately, either himself or with others in order to grow. The basic assumption of this thesis is that the human personality can develop optimally if the interaction between individuals with the environment (eco-cultural) goes well. Evident that the ecological aspects (cultural and social) give strength in the development of the individual.

The process of providing assistance in counseling perspective development is a model that dotted press on the human dimension (human effectiveness model). The dimensions are emphasized in this model are the roles and relationships (roles and relationships), behavior resolve the problem (coping behaviors), and the task of development (developmental tasks). The first dimension is the role and relationship of individuals whose purpose 
is to develop the role of the counselee as individuals and how that role can make a positive contribution to the individual when interacting with the environment (other people). The second dimension is the behavior in a strategy to face the problem. Step coping behaviors are specific instruments to do the individual in a transaction with the structure of the environment. Copping is not the same as the process of adjusting to the environment but coping interpreted to avoid environmental that nirnalar (unreasonable), arbitrary, and without force rules (capricious). Counselee sensitivity and awareness of the environment (ecological awareness) became one of the important things in development. The third dimension is the task of development, how a counselor is able to facilitate the tasks of individual development.

The paradigm that developed by Blocher implicates for professional practice model. In the professional services of modern (future development of psychoanalysis) counseling approach is often referred to as a model of community mental health (community mental health model), a model of counseling and psychotherapy oriented face to face as individuals by using one or several instruments or interventions provided in practice professional (Corey, 2009: 17), in the educational setting, the model is often referred to as outreach approach. In the next development of professional workers are required to be proactive rather than reactive, active to condition the environment or counselee potency as one of the efforts to develop and improve the environmental quality of the counselee. Then the counselor understanding of the various cultures (multicultural) became one of the competencies for professional workers. The impact of counseling paradigm shift affects the mechanism of the counseling process, counseling is not only where the interaction occurs through counseling interviews between individuals but the concept of empowerment (empowerment) and individual-social assistance into a new trend.

Comprehensive guidance and counseling essence lies in the process of facilitating the development of individuals in their environment. Development occurs through healthy interactions between individuals with the environment, and therefore, efforts focused guidance and counseling also to efforts to build healthy human development environment (ecology of human development) (Kartadinata, 2011: 58).

Guidance and counseling study that emphasizes the environment counselee better known as the ecological approach. The focus of the ecological approach is the relationship and interaction between the development of human and social environment, physical and psychological. Guidance and counseling to facilitate individuals to learn and develop long-term behavior through healthy interactions and transactions between the individual and his environment (Kartadinata, 2011: 61). Based on this understanding, it is important for the counselor to have a vision or eco-literacy paradigm, then the counselor is able to run a pedagogy service that understanding- centered of life so that the counselee is able to overcome the problem of alienation toward nature and able to revive the counselee about the spatial sensitivity.

Individuals with the environment or society (social) is a unity that could not be separated. It will cause some problems between identity and conformity if the individual is considered as the smallest unit of society that could not be parsed again as the views of classical physics considers atomos is the smallest form that could not be parsed again. Individuals actually are not something that is really single, but as a uniqum which is unique 
among other individuals, so that unity in the social bond is not regarded as an allround picture fetter and limit personal individuality. Hence, it is very important to lay the individual and society in a mutualism relationship, namely togetherness internalized by individuals as "Kita" (We, I-Thou). Here, we see the relevance of this ancient wisdom with psychology and quantum physics about the reality of the "binary opposition" or "contraria" complementary (sunt complementa).

In the context of guidance and counseling, through grasping the meaning of ancient oriental wisdom, then guidance and counseling will no longer stutter to understand the concept of multicultural practices and services. Counseling, especially in the West remain uncertain grasp of multicultural counseling, but counseling multicultural become an important part of literacy psychology in recent decades (Ancis \& Marshall, 2010). It begins, during the past 60 years, there is growing interest in diversity-sensitive counseling (Mufrihah, 2014). Multicultural counseling in the West (America) its issues are emerging in the early 1960s, hereinafter underlie consciousness of Americans in the 1980s. However, apparently this awareness is accompanied by the reappearance of racist attitudes which divide and they are increasing as well (Hansen, 1997: 41).

Uncertainty multicultural counseling in the West comes as a debate in the field of multicultural counseling, most parties support what is known as the etic perspective, stating that there is a universal quality in counseling that can be generalized to all cultures. While on the other hand, their emic perspective, assumes a counseling approach, must be designed specifically for each culture. Debate dwell on the perspective of "I / we" to "you / you all" or "he / they" were not led. Therefore, in the 21st century, the definition of multicultural counseling should be revisited by using the perspective of "Kita".

Multicultural counseling approach by using the perspective of "We" can be gained from the tradition of language (linguistic) oriental already familiar with the use of vocabulary "We", thus it can be said in the understanding of cultures, nations in the East are more advanced than the West. Already since the 14th century, $\mathrm{Mpu}$ Tantular proclaiming Bhineka Tunggal Ika (Unity in Diversity), diverse but one, which was then the nation's founders made the symbol of the country after a long journey since 1928 with Soempah Pemoeda which establishes the Indonesian language as the national language is not the language Javanese or Sundanese if views from many users native language. Something unique in Indonesian is the introduction of the vocabulary of "We", is consistent in the kanji Chinese vocabulary "We", the Chanmen, besides Wo-men (I / us), Nie-men (you / you all), and Ta-men (he / they). There is no substitute "we" in language vocabulary of the West, for example in English consist of I, we, you, He / She, They.

The relation "We" or I-You (I-Thou relationship) by Martin Buber (1970) is to describe the relationships among personal that sincere or true, contrasting with one form of relations, namely the I-it relationship. In the relationship I-You, individuals are aware and appreciate partner relations as a subject like himself, subject to his own world, a subject that is always in the process, and subjects who have feelings, thoughts, and his own. Individual attitudes of this kind enable the individual to have some willing to give empathy to peer (partner) relationships, which in turn makes people able to try to imagine what and how the visible world and the subjective perspective of the relationship colleagues (Clark, 2010). It is 
different with relation I- you, in the relation called I-it relationship people viewed relations not as subjects, but as objects; an object that can be ignored or used for personal benefit to the individual. So, in this kind of relationship, there is no willingness to give empathy to peer relations and, therefore, there is no ability for the individual to understand the world of peer relationships.

In very simple it can be concluded that the multicultural counseling with emic perspective refers to the counselor view towards counselee culture, while etic refers to the views of the overall culture counselor in the counseling process. Multicultural counseling with the perspective of "Kita" (I-Thou) is to combine emic and etic perspective. In the process of counseling relationships, the taken approach is to understand the counselee completely. Understanding counselee completely means that must to do is understanding the specific cultural influences counselees themselves, understand the uniqueness of the counselee and understand people in general or universal in nature overall (etic). But in understanding the specific cultural means should understand and comprehend the culture brought by the counselee as a result of socialization and adaptation counselee of the environment. This is very important because every counselee will bring their own culture (emic).

Guidance and counseling did not stop the multicultural diversity or diversity per se, but rather on how the counselor together counselee can recognize, accept, and understand the differences that could not be discharged in the counseling service. Thus, the implementation of counseling services that involve a counselor to one or a number of counselees not only to show the differences and diversity, but more can be reconciled with the reality, so counseling services proceed according to the plan; counselor does not intervene counselee based on his values and beliefs, and counselees continue to be optimal to develop values and beliefs in a positive direction.

\section{Holistic Vision: Forward Directions of Counseling}

Based on the idea Capra and the exposure of the nature of the principle of comprehensive (comprehensive in scope) in guidance and counseling above, how the direction of the development of the science of guidance and counseling for the future? What attitude and thinking can be used for the advancement of guidance scientific and counseling?

Human problems, especially counselee is very complex and large, so it can not be solved partially, then it should to make cooperation, communication, and system support among stakeholders. In fact, communication between the field of profession and science is important, it is necessary for openness to all stakeholders. It is needed for synergistic cooperation in dealing with problems of the counselee. Synergistic cooperation requires that the differences and particularities are recognized and appreciated. In the synergistic cooperation is necessary to develop trust between related fields, it is also important to the counselee placed confidence, that the counselee is able to overcome himself.

The paradigm of guidance and counseling in thinking frame of the Eastern-style model of quantum physics also teaches to more develop a model of thinking that balanced, comprehensive, thorough. The life, especially the issue of human behavior, has many dimensions and aspects. In order to find solutions to complex human problems, it is needed for approach and way of thinking that is more extensive and comprehensive. So, no matter how small the individual issues, it 
is important to be known by considering every aspect. Guidance and counseling services should be anticipatory (preventive) and not get stuck in an instant and partial handling, so the problems are not resolved properly. In this context, it is necessary to develop an attitude and thinking that balanced and aligned. Balanced means all aspects considered, harmony in action. In harmony, the action that caused the damage would have been avoided.

Thinking model of quantum physics will also sensitize human limitations. The limitations of our own thoughts that were not able to solve all the problems. Aware that every thought has limitations. Awareness of these limitations become very important, especially for practitioners (counselors), researchers, academics of counseling and guidance field to continue the reflectionintrospection about what has been, is doing and will be done in order to advance the counselee's life and humanity at large.

Through a comprehensive paradigm, guidance and counseling need to prepare experts in order to develop a thorough awareness of thinking, simply need to develop a vision or a holistic view in guidance and counseling. Through a holistic vision, all terms of the ability of individuals considered integrally, such as intellectual ability, emotional, social, physical, artistic, creativity, and spiritual. Each person helped to realize to discover and develop their identity and find meaning and purpose of life through mutual entanglement with the environment, society, others, nature and the Creator. The attachment should not be forgotten in guidance and counseling activities, then every individual involved in the process of active guidance and the enhanced sense of responsibility (responsibility), personal and social. Because as a pedagogical efforts, guidance and counseling aimed at helping people achieve self-realization, find themselves as individual beings, socially and spiritually (Kartadinata, 2011: 47).

A holistic approach departs from the understanding of human nature that leads toward being (be exist). Being exist personally always mean being exist together with another person. Man that are single and alone without any other human contact is incomplete, even negate the fact. Then the existence of the individual as well as understanding ecoliteracy, always intertwined with the world: environmental, familial, and societal. In short, the essence of human existence is in the togetherness. But togetherness is not portrayed solely as shackles to limit personal individuality. In terms of Honneth (Runesi, 2014), subjectivity must be addressed by developing a paradigm of intersubjectivity. As a uniqum, every person (subject) only thrive and live liberty instead of being together (intersubjective). Their relationship is this intersubjective appreciation of themselves as freedom can be obtained at all times and not just to be alone. Individuals with other individuals together to establish the significance of social (social meaning) towards the ideal life and intact. Social man is not a coincidence; it is something that should exist, because unity in togetherness is the essential characteristic of human existence, in terms of Heidegger, Sein ist Mit-Mensch-Sein, human existence is being together-existence.

Based on the above understanding, the guidance and counseling services with a holistic approach means that respect the principles of togetherness (democracy), stressed the dialogic process (Strong \& Zeman, 2010), see freedom as a choice. Based on this principle, the counselor is responsible for the system of shared values of counselee, as long as it does not contradict with moral principles. Counselors are required to behave 
rationally, ethically, build value in depth, and encourage counselees to be responsible for his choice.

Guidance and counseling with holistic vision means doing more interdisciplinary approach, integrated, forward the elements of dialogue, empathetic, reflective, critical, flexibility, collaborative, and creative. Clarified by Kartadinata (2011: 64), counselor when performing the services, must be competent in terms of understanding the complexity of the interaction of individuals in diverse social and cultural context (multicultural), master in various forms of intervention psychopedagogy's, master the strategy of environmental assessment in relation to the functioning of the individual in the environment, and understand the process of human development.

\section{CONCLUSION}

The development of the concept of guidance and counseling services are paradigmatic influenced by the theoretical framework developed in times of developmental theories of counseling and psychotherapy. Freudian concepts, behavioristic, humanistic and system approach also affected the development of guidance and counseling services. Pattern of forward tendency, guidance and counseling, as well as the same trend, occurred in other disciplines engaged in a holistic approach.

Through a comprehensive paradigm to think holistically, counseling and guidance needed to prepare the experts to be able to develop a thorough awareness of thinking, more humane, integrated and holistic vision. With a holistic vision, all terms of the ability of individuals considered integrally, such as intellectual ability, emotional, social, physical, artistic, creativity, ecological intelligence, and spiritual. Practitioners and academics guidance and counseling must think holistically aware of the limitations of self, so that will always set himself towards perfection even higher. Thus, guidance and counseling with a holistic approach to developing into a noble profession. Feature of noble profession than the usual profession, namely their commanding the good spirit of altruistic or selfless, amar ma'ruf (order good deeds profitless), nahi munkar (prevent evil deeds) of the symptoms irregularities that potentially degrade the profession, do esprit de corpse to retains the nobility of the profession. Only with such spirit, a together life together can be saved.

\section{REFERENCES}

Ancis, J. R. \& Marshall, D. S. (2010). Using a multicultural framework to assess supervisees' perceptions of culturally competent suvervision. Journal of Counseling and Development, 88(3). 277-284.

Blocher, D. H. (2000). The Evolution of Counseling Psychology. New York:Springer Publishing.

Buber, M. (1970). I and Thou. New York: Scribners.

Capra, F. (1991). The Tao of Physics: An Exploration of the Parallels BetweenModern Physics and Eastern Mysticism ( $3^{\text {rd }}$ edition). Boston: Shambala.

Capra, F. (200o). Titik Balik Peradaban. Yogyakarta: Bentang.

Clark, A. J. (2010). Empathy: an integral model in the counseling process. Journal of Counseling and Development, 88(3). 348-356.

Corey, G. (2009). Theory and Practice of Counseling and Psychotherapy ( $8^{\text {th }}$ edition). Belmont, CA: Thomson Brooks/Cole.

Gojali, M.(2012). Psikologi Islami (Sebuah Pendekatan Alternatif Terhadap Teori-teori Psikologi Barat) [online].

Tersedia: http://www.tasawufpsikote rapi.web.id/2012/05/psikologiislami-sebuah-pendekatan.html [21 September 2015]. 
Frankl, V. (2004).On the Theory and Therapy of Mental Disorders: An Introduction to Logotherapy and Existential Analysis. New York: Brunner-Routledge.

Hansen, L. S. (1997). Integrative Life Planning; Critical Tasks for Career Development and Changing Life Patterns. San Francisco: Jossey-Bass Publishers.

Purwadianto, A. et al. (2004). Jalan Paradoks Visi Baru Fritjof Capra Tentang Kearifan dan Kehidupan Modern. Jakarta: Teraju.

Kartadinata, S. (2011). Menguak Tabir Bimbingan dan Konseling Sebagai Upaya Pedagogis. Bandung: UPI Press.

Mufrihah, A. (2014). Implikasi prinsip bimbingan dan konseling terhadap kompetensi multikultural konselor. Jurnal Pelopor Pendidikan, 7(1). 7385 .

Runesi, Y. T. (2014). Pengakuan sebagai gramatika intersubjektif menurut Axel Honneth. Melintas, 3o(3). 323-345.

Sanyata, S. (2013). Paradigma bimbingan dan konseling:pergeseran orientasi dari terapeutik-Klinis ke preventifperkembangan. Jurnal Paradigma, 15(8). 1-9.

Strong, T. \&Zeman, D. (2010). Dialogic considerations of confrontation as a counseling activity: an examination of allen ivey's use of confronting as a microskill. Journal of Counseling and Development, 88(3). 332-339. 